in this respect. In fact, the general fastness of lac dyeings made it appear to me a matter of surprise that this material has been so completely superseded by synthetic dyes, the more so as it is necessarily obtained as a by-product in the purification of lac, a material for which there is an ever rapidly increasing demand.

\section{CONCRETE RAILWAY TIES.}

(From Daily Consular and Trade Reports, No. 3326, Nov. 9, 1908.)

In the preparation of the following report concerning the manufacture of reenforced cement railway ties in Italy Consul Chapman Coleman, of Rome, says that the information was furnished by the Italian state railway authorities, the Gabellini Cement Company, and others:

The Italian Government has ordered 300,000 of these ties, which are now in course of construction. A few thousand of such ties, ordered for experimental purposes, were constructed by the Gabellini company some years ago, and have been used on the railroad from Castellamare-Adriatico to Ancona. As a result of the trials to which the ties were subjected a new design, to be employed in executing the present large order, will replace the old. The principal change will, it is understood, be found in the introduction into the concrete mass of a larger number of the reenforcing metallic bars, of reduced diameter, in the new design of ties.

The cost of a concrete tie is estimated at about $\$ 1.20$, and it is believed that its endurance will be from three to four times as great as that of a wood tie. A tie will weigh about 286 pounds, inclusive, of the weight of the metallic reenforce ment, about 28 pounds. A comparison of the respective cost and value of concrete and wooden ties would no doubt give different results in the United States from those afforded in the Italian estimates, owing to varying conditions in the two countries affecting local cost of materials and manufacture, endurance, etc. The belief is largely entertained here that the concrete tie will eventually entirely replace wood tie.

SPECIFICATIONS FOR REENFORCED CONCRETE TIES.

The following are the principal features of the technical specifications respecting the furnishing of ties of reenforced cement to the Italian state railways:

The materials to be used in construction are normal Portland cement, sand in grains of two sizes, round iron bars, and braces of wood. The cement must not contain impurities of any sort, nor more than 2 per cent. of sulphur in any state of oxidation. The tests of the purity of the cement must not show variations in volume nor excessive heat during the process of setting. Tests mechanically conducted with normal sand, which has been kept for twentyeight days under water, must show a coefficient of resistance to strain of not less than io kilos per square meter and a coefficient of resistance to compression of not less than 100 kilos to the square centimeter. The sand must be calcareoussilicious, containing about 30 per cent. of silex, must be nonbituminous, and must consist of grains of two sizes the half of the quantity necessary must be passed through a screen with circular holes of 5 millimeters in diameter; the other half must be normal sand.

At equal prices preference will be given to artificial sand obtained by the crushing of calcareous-silicious stone, pro-

J. Soc. Chem. Ind., 14, 460 (1895). viding the products respond to the above indicated conditions and the stone resists breaking under a pressure of not less than 500 kilos to the square centimeter. The round reenforcing bars of the ties must support three bending tests at a temperature of 20 degrees of cold. The use of zinc iron is excluded. Braces must be of wood of strong fiber (male uak, bitter oak, hornbeam, walnut, acacia, etc). The woud must be well seasoned and derived from trees felled while green and at the proper season of the year. They must be thoroughly permeated with tar oil and must not contain cracks or other defects which may prejudice the use for which they are intended. No tolerance will be given in the dimensions of the braces; they will be provided at the cost of the furnishing firm and will be subjected to examination by the agents of the state railways before acceptance.

In the construction of the ties a paste or admixture will be employed which shall contain a cubic meter of sand (one-half large, the other normal), 750 kilos of normal Portland cement, with the addition of a little water to give the mass a moist consistency. The sand will be washed with clean water, and so carefully and thoroughly that when fresh water is again applied it will be found to remain perfectly clear.

This mass must be diligently compressed around the armature, either by hand or mechanically. For compression by hand work, pestles of a weight not inferior to 750 grams will be employed, and the material to be compressed will be applied in strata of not less than 2 centimeters in thickness and will be continued until complete adjustment is attained. For mechanical compression a pressure nòt inferior to 25 kilos per square centimeter must be employed and applied at the same time to the entire tie.

The ties, as soon as formed and without having been subjected to any bending strain, must be placed upon an even, unbroken surface and covered with powder tufa or earth material, and must be kept constantly moist for at least fifteen days. After twenty days the ties may be sacked, but must be protected from the action of atmospheric agents for a further period of at least ten days. The ties may be entirely submerged in water, but only after setting has taken place

The agents of the administration of state railways will supervise the manufacture of the ties and will assure themselves that the conditions of these specifications are observed, and will therefore have the right of free entrance to the plant of the furnishing firm at all times. They will also be entitled to break open one tie for every thousand in order to ascertain whether the reenforcement has been done with iron bars of the prescribed diameter; and whenever it is found that bars of a less diameter have been used, the entire quantity under manufacture will be rejected.

The furnishing firm is required to guarantee the ties for one year from the date of the last receipt of consignment and to replace or refund the price of any ties which it has become necessary to remove during the period of guaranty because of their unserviceable nature, resulting from defective manufacture; and action in this regard is to be left to the exclusive judgment of the administration of the state railways.

Diagrams showing the detailed Italian construction and manufacture and test of concrete railway ties may be seen at the Bureau of Manufactures. 